\title{
INFILTRAÇÃO LEPTOMENINGEA POR GLIOBLASTOMA MULTIFORME DA MEDULA CERVICOTORÁCICA
}

\author{
A. SPINA-FranÇa * \\ A. ANghinah ** \\ J. SAllum ***
}

A incidência do glioblastoma entre os tumores medulares é relativamente baixa. Kernohan e Sayre ${ }^{3}$, basendo-se na revisão de 979 tumores intrarraqueanos, verificaram que 22,5\% correspondiam a gliomas intramedulares. Entre êstes havia nítido predomínio dos ependimomas; em proporção menor ocorriam os diversos tipos de astrocitoma, tendo sido raro o encontro de oligodendrogliomas. Para 200 dêsses gliomas intramedulares, verificaram êles 14 casos apenas de astrocitoma grau 3 ou 4, equivalentes - na classificação respectiva - em especial ao glioblastoma multiforme, da classificação de Bailey e Cushing.

Dados de outros autores permitem avaliar também a pequena incidência do glioblastoma medular. Woods e Pimenta ${ }^{8}$, analisando 68 casos de processo intramedulares, citam apenas dois pacientes com glioblastoma entre 35 com tumores. Arseni e Ionesco ${ }^{1}$, numa revisão de 362 casos de tumores intrarraqueanos, encontraram só dois de glioblastoma, ambos de localização cervical. Guidetti ${ }^{2}$, revendo 71 casos de tumores intramedulares, encontrou 4 glioblastomas.

Roth e Elvidge ${ }^{6}$, ao analisar 404 casos de glioblastoma, relataram apenas 6 em que o tumor se desencolvera primitivamente na medula espinhal. Esse dado ganha maior realce quando lembrada a incidência geral do glioblastoma entre os tumores gliais do sistema nervoso central. Polmeteer e Kernohan ${ }^{5}$ citam que Elvidge, Penfield e Cone encontraram 55 casos de glioblastoma entre os 210 gliomas por êles revistos, perfazendo a proporção de $26 \%$.

Dos tumores gliais, os meduloblastomas são aquelas que mais comumente invadem as leptomeninges. Polmeteer e Kernohan ${ }^{5}$, analisando 42

Do Departamento de Neurologia (Prof. A. Tolosa) e do Departamento de Anatomia Patológica (Prof. C. Mignone) da Faculdade de Medicina da Universidade de São Paulo: * Professor assistente e Docente Livre; ** Professor assistente; *** Instrutor. 
casos de infiltração meníngea por gliomas, verificaram que ela dependia de meduloblastomas em cêrca de metade (20 casos). Nessa mesma estatística, o glioblastoma era responsável pela invasão em 6 casos.

Três são os modos considerados como principais na infiltração leptomeníngea por gliomas ${ }^{3,5}$ : o primeiro é o da invasão local, em continuidade ao tumor; o segundo é o do acometimento sub-aracnóideo difuso por células oriundas do glioma inicial, levando a metástases leptomeníngeas multíplas (gliomatose meníngea); o terceiro, raro, é o do desenvolvimento do tumor a partir de tecido glial heterotòpicamente situado nas leptomeninges. Segundo O'Connell 4, é mais comum a difusão sub-aracnóidea de tumores intracranianos para as meninges raqueanas que a difusão de tumores medulares para as meninges encefálicas. Esta última possibilidade é ilustrada por êsse autor mediante o relato de três casos, dois dos quais de difusão de glioblastomas medulares. Embora a gliomatose meníngea possa resultar de invasão sub-aracnóidea por glioblastomas, não é ela o modo mais comum pelo qual êsse tumor invade as leptomeninges. A expansão subaracnóidea em direta continuidade ao tumor primitivo é observada com maior freqüência. $\mathrm{Na}$ estatística de Elvidge, Penfield e Cone, referida, a infiltração meníngea foi verificada em $8 \%$ dos casos de glioblastoma.

Ésses dados justificam o registro do caso de paciente com glioblastoma da porção cervicotorácica da medula que infiltrava as leptomeninges. No espaço sub-aracnóideo o tumor formava manguito que envolvia a medula desde a dilatação cervical até a região lombar.

O B S E R V A C $\mathrm{O}$

A.P. (registro H.C. n. 818.303), branco, sexo masculino, com 17 anos de idade, lavrador, internado em 2-janeiro-1967. Moléstia iniciada cêrca de 15 dias antes por quadro de retenção de urina e de fezes, logo seguido de adormecimento e perda de movimentos no membro inferior direito. Aos poucos a sintomatologia propagou-se para o membro inferior esquerdo, tornando impossível a deambulação. Ao ser internado o paciente queixava-se de impossibilidade de mover os membros inferiores, adormecimento do corpo abaixo do nivel da cicatrtz umbelical e de não evacuar nem urinar espontâneamente. Exame clinico-neurológico Pulso 80 batimentos/minuto; pressão arterial $110 \times 70 \mathrm{~mm} \mathrm{Hg}$; temperatura $37,5^{\circ} \mathrm{C}$; paciente consciente, em regular estado geral. Nada de particular foi notado no exame dos diversos aparelhos. Abolição dos movimentos voluntários e da fôrça muscular nos membros inferiores; reflexos aquilianos presentes e simétricos; reflexo patelar direito abolido e esquerdo vivo; reflexo dos adutores abolido no lado díreito e vivo à esquerda; reflexos cutâneo-abdominais, cremasterinos e cutâneoplantar abolidos bilateralmente. Hipestesia táctil, térmica e dolorosa do quarto ao décimo metâmeros torácicos, bilateralmente, e anestesia abaixo dêsse nivel; apalestesia a anartrestesia nos membros inferiores. Retenção urinária e fecal. Nos membros superiores e no segmento cefálico o exame neurológico era normal. Exames complementares - Liquido cefalorraqueano (LCR) colhido mediante punção lombar: pressão inicial $21 \mathrm{~cm} / a ́ g u a ;$ prova manométrica de QueckenstedtStookey mostrando bloqueio completo do canal raqueano; LCR límpido e xantocrômico, tendo coagulado espontâneamente; exame citológico prejudicado; proteínas totais $1800 \mathrm{mg} / 100 \mathrm{ml}$; cloretos $580 \mathrm{mg} / 100 \mathrm{ml}$; glicose $40 \mathrm{mg} / 100 \mathrm{ml}$; reaçóes de fixação do complemento para sifilis e para cisticercose negativas. Radiografias da coluna dorsal normais. Perimielografia descendente: bloqueio completo do canal 
raqueano a partir do nível da primeira vẻrtebra torácica (Fig. 1). Revisão dêste exame um mês depois mostrou que o bloqueio permanecia inalterado, sendo as imagens sugestivas de processo expansivo intramedular, embora não permitisse excluir a presença de aderências meningomedulares.
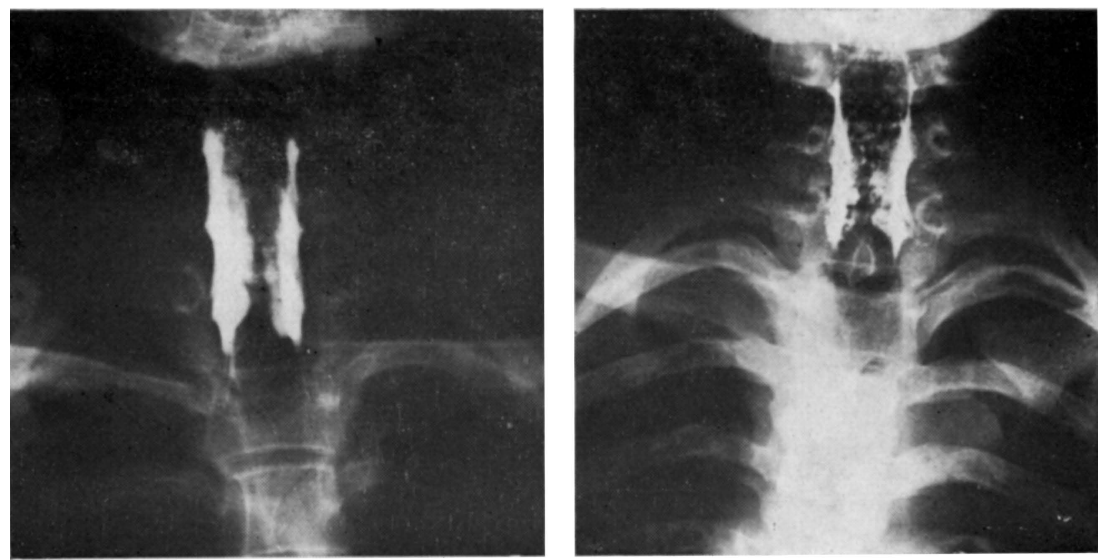

Fig. 1 - Caso A. P. Perimielografia descendente: bloqueio completo do canal raqueano ao nivel da primeira vértebra torácica. Aspecto inicial do exame e da revisão, cêrca de um mês depois.

Evolução - O quadro clínico permaneceu inalterado até maio-1967, quando surgiram dores no pescoco e nos membros superiores, nos quais instalou-se também comprometimento da motricidade. A êsse quadro associou-se pouco tempo depois sintomatologia de hipertensão intracraniana. O exame neurológico mostrava: tetraplegia flácida, abolição dos reflexos musculares profundos (exceto dos patelares, que se achavam diminuidos), amiotrofias nas mãos; hipestesia superficial a partir do terceiro metâmero cervical que se estendia até o segundo torácico, a partir do qual havia anestesia para tôdas as formas de sensibilidade. Edemas das papilas ópticas. O comprometimento esfincteriano permanecia inalterado. Escaras nas regiões sacra e maleolares.

Em 8 de junho o paciente foi submetido a exame do LCR mediante punções combinadas. A punção sub-occipital mostrou pressão inicial de $80 \mathrm{~cm} / a ́ g u a$, LCR límpido e incolor, com 4 células $/ \mathrm{mm}^{3}, 40 \mathrm{mg} / 100 \mathrm{ml}$ de proteínas totais e $58 \mathrm{mg} / 100 \mathrm{ml}$ de glicose. A punção lombar mostrou pressão inicial de $47 \mathrm{~cm} /$ água e bloqueio completo do canal raqueano à prova de Queckenstedt-Stookey; o LCR era límpiđoo e xantocrômico e apresentava 2,3 células $/ \mathrm{mm}^{3}$, $1550 \mathrm{mg} / 100 \mathrm{ml}$ de proteínas totais e $43 \mathrm{mg} / 100 \mathrm{ml}$ de glicose.

Em 30 de junho, após tentativa sem sucesso de angiografia pela artéria vertebral esquerda, o paciente apresentou parada cardiaca e respiratória. Mediante massagem cardíaca externa houve recuperação dos batimentos cardíacos após cêrca de 20 minutos. O paciente - mantido com ventilação pulmonar controlada desde então - permaneceu em coma, vindo a falecer dois dias depois.

Exame anátomo-patológico - Anemia dos pulmões, miocárdio, mucosa gastrointestinal e rins. Lipoidose da aorta. Esteatose renal. Encéfalo pesando $1600 \mathrm{~g}$ com edema cerebral. Medula espinhal com volume e consistência aumentados em tôda a sua extensão, particularmente na metade superior. Aos cortes verifi- 
cava-se que sua estrutura era totalmente substituída por tecido neoplásico, em parte necrosado, ao nível da porção cervical inferior (Fig. 2). A partir dêsse nível o tecido neoplásico invadia as leptomeninges e raizes raqueanas circunjacentes. Os cortes de outras regiōes da medula mostravam que o tecido neoplásico invadia a porção central da dilatação cervical, bem como as porções superior e média da medula torácica. Necrose isquêmica no restante da medula cervical, sendo total em sua parte alta. Nas porções torácica inferior e lombar a estrutura

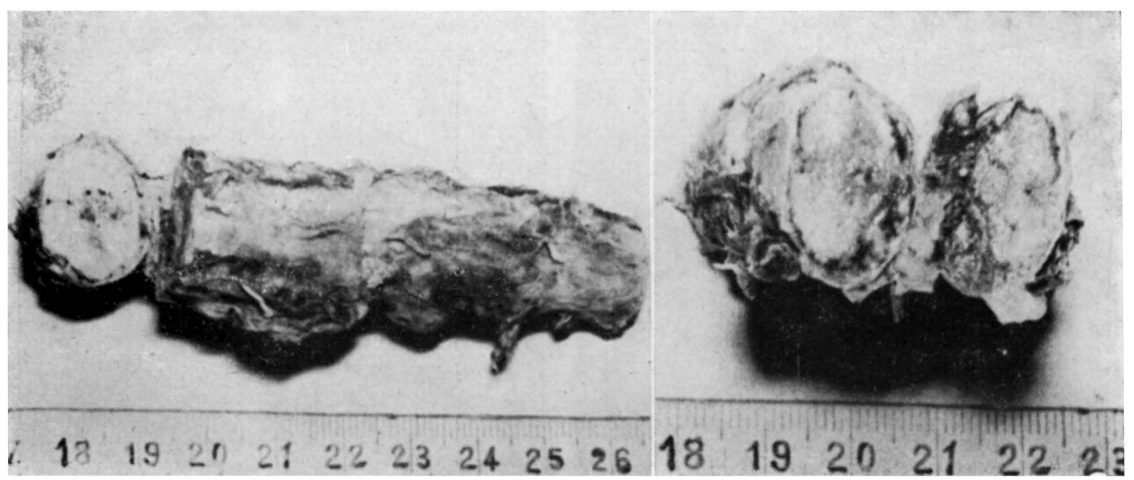

Fig. 2-Caso A.P. Exame macroscópico da medula cervical. Seções transversais na porção cervical alta (à esquerda) e na dilatação cervical (à direita).

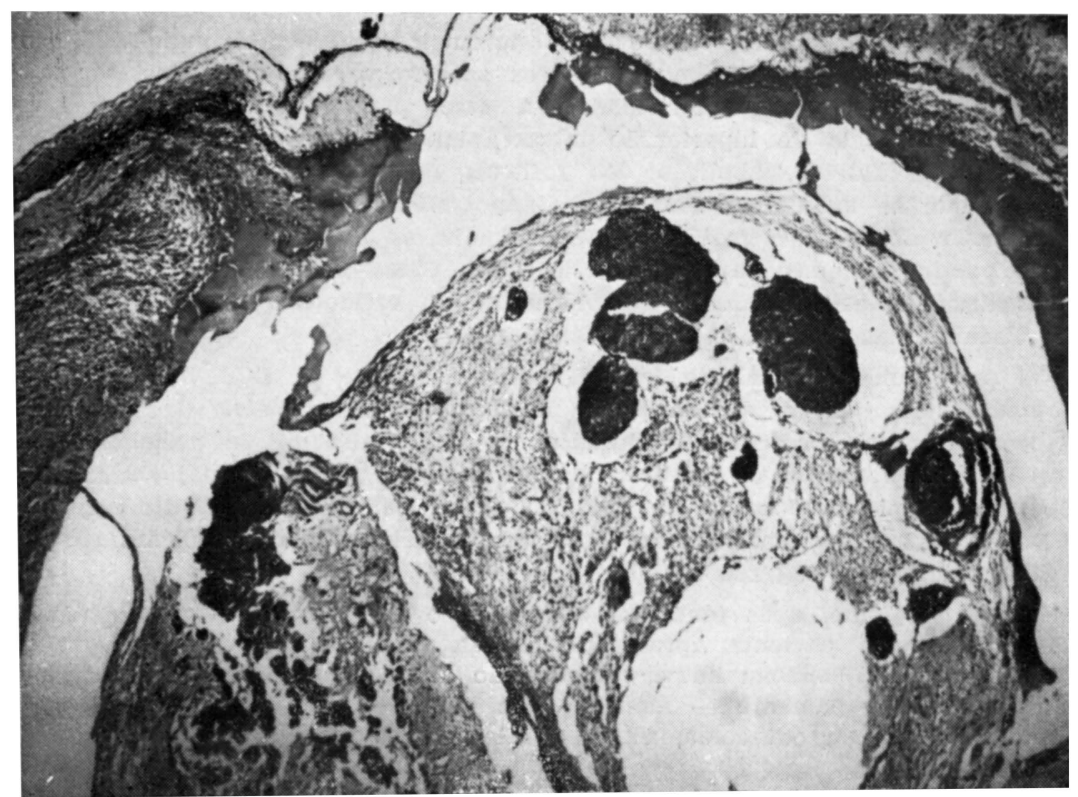

Fig. 3 - Caso A.P. Secção mostrando a invasão leptomeníngea pelo tumor que cresce no espaço sub-aracnóideo e envolve raizes raqueanas (Hemat.-eosina; $\chi$ lupa). 
medular era normal. A infiltração leptomeníngea pelo tecido neoplásico verificada em continuidade com aquêle da parte inferior da medula cervical se estendia a montante e a jusante, formando manguito que invadia o espaço sub-aracnóideo (Fig. 3). A montante êle se estendia até o nivel da dilatação cervical e a jusante até o da região lombar. Ao nível da região cervical alta e no compartimento intracraniano as leptomeninges se achavam normais. O estudo histopatológico do tumor mostrou tratar-se de glioblastoma multiforme (Fig. 4).

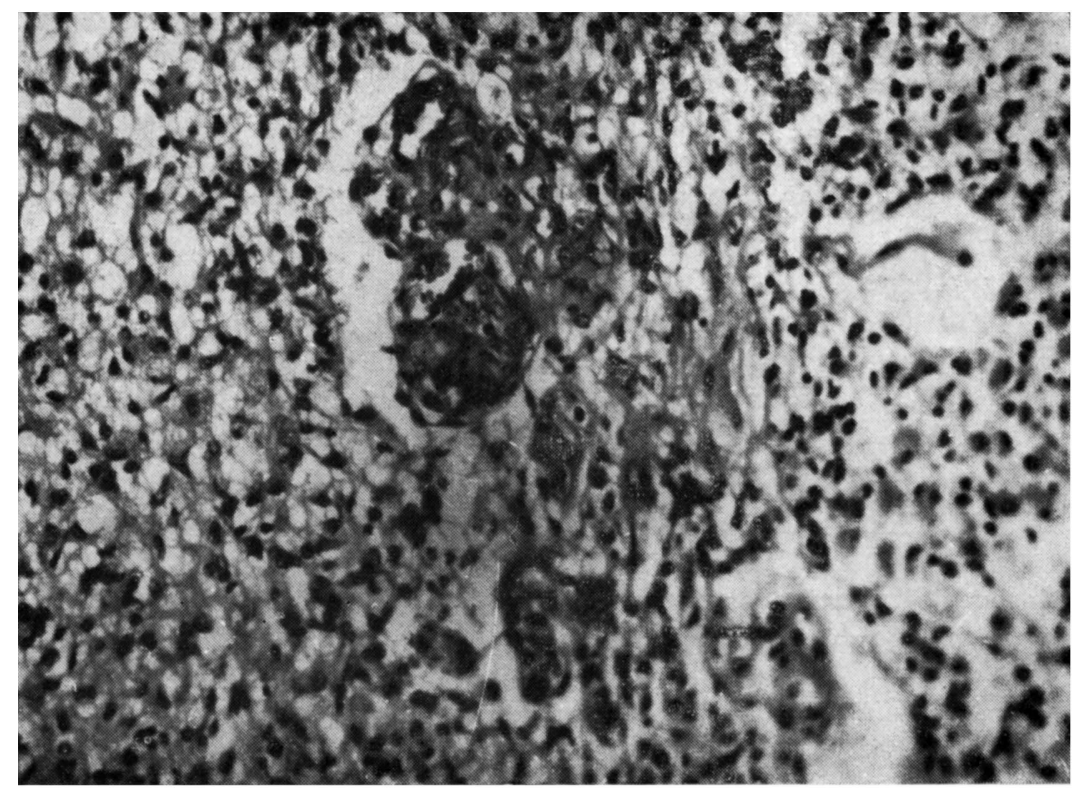

Fig. 4 - Caso A.P. Secção do tumor, notando-se o aspecto imaturo de suas células e a hiperplasia das paredes vasculares (Hemat.-eosina $\chi 160$ ).

\section{COMENTARIOS}

O quadro de mielopatia transversa de nível torácico alto que caracterizou o início da doença evoluiu de modo rápido. Cinco meses depois da sintomatologia inicial os sinais clínicos sugeriam o acometimento de metâmeros cervicais altos. Esse quadro de mielopatia ascendente era acompanhado de sinais de comprometimento motor de tipo periférico, em especial nos membros superiores. As amiotrofias, particularmente nítidas nas mãos, salientavam-se dentro dêsse quadro. Dôres que se irradiavam segundo territórios radiculares cervicobraquiais surgiram também nessa fase. No final da evolução à sintomatologia mielorradicular ascendente associou-se quadro de hipertensão intracraniana, em cuja vigência o paciente faleceu.

O bloqueio completo do canal raqueano, demonstrado por ocasião do primeiro exame do LCR lombar, levou a que fôsse feita perimielografia descendente que permitiu verificar que o bloqueio era devido a provável tumor intramedular situado ao nível da primeira vértebra torácica. 
O quedro final de hipertensão intracraniana levou à hipótese de que o tumor, crescendo em sentido cranial, invadira a fossa posterior. Essa hipótese não foi confirmada pela necrópsia: edema cerebral foi o único achado patológico em relação ao encéfalo. Da mesma forma, foi verificado que o comprometimento da medula acima da dilatação cervical era devido a necrose isquêmica.

O tumor se estendia da porção central da dilatação cervical da medula até a região torácica média; na parte inferior da medula cervical as estruturas normais se achavam pràticamente substituídas por êle. Era a partir dêsse nivel da medula que o tumor invadia as leptomeninges, estendendo-se pelo espaço sub-aracnóideo em sentido cranial e caudal, formando manguito perimedular que a envolvia desde a dilatação cervical até sua porção lombar. Histològicamente foi o tumor reconhecido como glioblastoma multiforme.

A infiltração meníngea dependia do mecanismo de projeção direta do glioma intramedular para o espaço sub-aracnóideo: sua expansão leptomeníngea guardava continuidade com porção intramedular. Não foram encontradas metástases gliomatosas em outros pontos do espaço sub-aracnóideo e não foi verificada a presença de células neoplásicas no LCR.

A hipoglicorraquia observada no caso é achado que tem sido descrito com certa freqüência em pacientes cujas leptomeninges são invadidas por neoplasias de natureza e malignidade diversa. Permanecem em plano hipotético as indagações sôbre os processos metabólicos dos qual resulta ?

\section{R E S M O}

Estudo anátomo-clínico de caso de paciente com glioblastoma multiforme da porção cervicotorácica da medula espinhal. A partir da sede primitiva o tumor invadia o espaço sub-aracnóideo, formando manguito que envolvia a medula desde a dilatação cervical até a região lombar. Apesar do crescimento tão extenso no espaço sub-aracnóideo, não foram encontradas metástases leptomeníngeas à distância. Considerações são feitas sôbre a freqüência com que o glioblastoma é observado entre os tumores medulares e sôbre os modos pelos quais êsse glioma costuma invadir as leptomeninges. Também no caso registrado foi verificada hipoglicorraquia, achado relatado com certa freqüência no comprometimento leptomeníngeo por neoplasias.

\section{S U M M A R Y}

Leptomeningeal infiltration by glioblastoma multiformis of cervico-thoracic region of the spinal cord.

The case of a 17 year old patient with glioblastoma multiformis of cervico-thoracic region of the spinal cord whose disease was first manifested almost 7 months prior to death is reported. Initial symptoms of 
sphincter disfunction were soon followed by clinical signs of transverse myelopathy in the upper thoracic region. A complete block of the spinal canal was found on manometric tests. The cerebrospinal fluid was xanthochromic and coagulated immediatly; total protein concentration was markedly increased and glycosis content was low. Descendent perimyelography showed that blocking was complete at the level of first thoracic vertebral body and that it was caused by an intramedullar expanding process. About two months before death symptoms referred to spinal cord impairment assumed an ascending character. Signs of peripheral motor neuron impairment appeared in the upper extremities. Progressive signs of intracranial hypertension appeared and preceeded death. A transient cardiac arrest and apnea occured. The patient, maintained under artificial respiration, remained in comatous state until death, two days later. Brain edema was found at post-morten examination. Cerebral meninges were normal. The upper portions of the spinal cord were enlarged and their consistency was increased. The structures of the inferior portion of cervical region were completely substituted by neoplasic tissue. The central portion of cervical enlargement as well as the upper and middle portions of thoracic region were also invaded by neoplasic tissue. Ischaemic necrosis occurred in the first cervical segments. Histologic examination showed that the tumor was a glioblastoma multiformis. In the inferior portion of cervical cord the neoplasy invaded the leptomeninges, growing extensively in the subarachnoid space, surrounding the spinal cord. Nerve roots were also invaded by neoplasic tissue. Literature data concerning to the low incidence of glioblastoma among tumors of the spinal cord were quoted. The leptomemeningeal invasion by the tumor found was discussed. In spite of its extension, meningeal gliomatosis was discarded since subarachnoid and medullar portions of the tumor were continuous, no metastatic tumoral growths related to other areas of subarachnoid space were found and tumor cells were not found in the cerebrospinal fluid.

\section{R E F E R E N C I A S}

1. ARSENI, C. \& IONESCO, S. - Les compressions medullaires dues à des tumeurs intrarachidiens. Etude clinico-statistique de 362 cas.J. Chir. 75:582$594,1958$.

2. GUIDETTI, B. - Intramedullary tumors of the spinal cord. Acta Neurochirurg. 17:7-23, 1967 .

3. KERNOHAN, J. W. \& SAYRE, G. P. - Tumors of the Central Nervous System. In Atlas of Tumor Pathology, section 10. Ed. Armed Forces Institute of Pathology, Washington, 1952.

4. O'CONNEL, J. E. A. - The subarachnoid dissemination of spinal tumors. J. Neurol. Neurosurg. Psychiat. 9:55-62, 1946.

5. POLMETEER, F. E. \& KERNOHAN, J. W. - Meningeal gliomatosis. A study of forty two cases. Arch. Neurol. Psychiat. 57:593-616, 1947. 
6. ROTH, J. G. \& ELVIDGE, A. R. - Glioblastoma multiforme: a clinical survey. J. Neurosurg. 17:736-750, 1960.

7. SUMI, S. M. \& LEFFMAN, H. - Primary intracranial leptomeningeal glioma with persistent hypoglycorrhachia. J. Neurol. Neurosurg. Psychiat. 31:190194, 1968.

8. WOODS, W. W. \& PIMENTA, A. M. - Intramedullary lesions of the spinal cord. Arch. Neurol. Psychiat. 62:383-399, 1944.

Clínica Neurológica - Hospital das Clínicas da Fac. Med. da Universidade de São Paulo - Caixa Postal $\$ 461$ - São Paulo, SP - Brasil. 